\title{
Analysis of structural diversity in wolf-like canids reveals post-domestication variants
}

\author{
Oscar Ramirez', Iñigo Olalde', Jonas Berglund², Belen Lorente-Galdos', Jessica Hernandez-Rodriguez', \\ Javier Quilez', Matthew T Webster ${ }^{2}$, Robert K Wayne ${ }^{3}$, Carles Lalueza-Fox', Carles Vilà ${ }^{4}$ \\ and Tomas Marques-Bonet ${ }^{1,5,6^{*}}$
}

\begin{abstract}
Background: Although a variety of genetic changes have been implicated in causing phenotypic differences among dogs, the role of copy number variants (CNVs) and their impact on phenotypic variation is still poorly understood. Further, very limited knowledge exists on structural variation in the gray wolf, the ancestor of the dog, or other closely related wild canids. Documenting CNVs variation in wild canids is essential to identify ancestral states and variation that may have appeared after domestication.

Results: In this work, we genotyped 1,611 dog CNVs in 23 wolf-like canids (4 purebred dogs, one dingo, 15 gray wolves, one red wolf, one coyote and one golden jackal) to identify CNVs that may have arisen after domestication. We have found an increase in GC-rich regions close to the breakpoints and around $1 \mathrm{~kb}$ away from them suggesting that some common motifs might be associated with the formation of CNVs. Among the CNV regions that showed the largest differentiation between dogs and wild canids we found 12 genes, nine of which are related to two known functions associated with dog domestication; growth (PDE4D, CRTC3 and NEB) and neurological function (PDE4D, EML5, ZNF500, SLC6A11, ELAVL2, RGS7 and CTSB).

Conclusions: Our results provide insight into the evolution of structural variation in canines, where recombination is not regulated by PRDM9 due to the inactivation of this gene. We also identified genes within the most differentiated CNV regions between dogs and wolves, which could reflect selection during the domestication process.
\end{abstract}

Keywords: Domestication, CNV, Candidate genes, Dog and wolf

\section{Background}

The use of mtDNA, microsatellites, SNP arrays and whole genome sequencing has revealed some of the genetic changes underlying the generation of phenotypic diversity under domestication. Specifically a small set of genes associated with phenotypic traits related to morphology, coat texture, color and behavior have been identified that are common to breeds sharing a similar phenotype [1-5]. Other studies have also provided insight into the selective forces at play during the process of domestication [6-9], admixture with wild

\footnotetext{
*Correspondence: tomas.marques@upf.edu

${ }^{1}$ Institut de Biologia Evolutiva (Universitat Pompeu Fabra - CSIC), Ciències Experimentals i de la Salut, Barcelona 08003, Spain

5 Institució Catalana de Recerca i Estudis Avançats (ICREA), Barcelona, Spain

Full list of author information is available at the end of the article
}

relatives $[10,11]$, or the population structure purebred and village dogs [12-14].

Structural variation refers to genomic alterations in the DNA content (insertions, deletions and inversions) greater than $50 \mathrm{bp}$ in size [15]. Although fewer studies of structural variation have been performed in dogs compared to studies using SNPs or microsatellite loci, some examples of copy number variants $(\mathrm{CNVs})$ that affect phenotype have been identified $[2,16,17]$. To date, four large-scale surveys of structural variation in dogs have been carried out using array comparative genomic hybridization $(\mathrm{aCGH})$ [18-21], providing the first catalog of CNVs in the dog genome and candidate CNVs for breed-specific traits. However, very limited knowledge exists on the evolution and timing of CNV events.

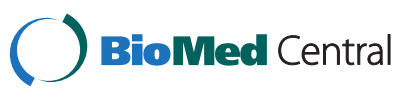

(c) 2014 Ramirez et al.; licensee BioMed Central Ltd. This is an Open Access article distributed under the terms of the Creative Commons Attribution License (http://creativecommons.org/licenses/by/4.0), which permits unrestricted use, distribution, and reproduction in any medium, provided the original work is properly credited. The Creative Commons Public Domain Dedication waiver (http://creativecommons.org/publicdomain/zero/1.0/) applies to the data made available in this article, unless otherwise stated. 
A variety of genetic mechanisms affect CNV dispersion in humans [22], the most common mechanism being non-allelic homologous recombination (NAHR), which involves the misalignment and crossover between regions of extended homology during both meiosis and mitosis. In humans, the zinc-finger protein PRDM9 is implicated in the CNV formation by NAHR [23]. The inactivation of this gene in the canid lineage [24,25] suggests that genomic features that promote the formation of $\mathrm{CNV}$ in canids might differ from the majority of mammals. Recently, Axelsson et al. [25] suggested that GC peaks represent novel sites of elevated recombination and genome instability in dogs, and Berglund et al. [21] proposed that these GC peaks were associated with the generation of many CNVs by NAHR events. However, the resolution of breakpoint in Berglund et al. was limited by the low density aCGH they used which precluded a fine-scale characterization of the regions. High-resolution approaches should provide new insight on the molecular mechanisms for $\mathrm{CNV}$ formation and dispersion in the genome. In addition, the analysis of outgroup species is needed in order to understand the origin and evolution of CNVs and their possible role in the origin of phenotypic diversity in domestic dogs. Specifically, the study of these loci in wolf-like canids, including the gray wolf (Canis lupus), the species from which domestic dogs derived, is needed to refine the assessment of ancestral states and variants that have appeared after domestication.

In this work, we designed a high density custom $720 \mathrm{~K}$ probe aCGH chip to systematically genotype 1,611 CNVs derived mainly from modern dog breeds [20] in a new panel of 4 purebred dogs, one dingo (a feral Australian dog, presumably isolated from other dogs during thousands of years), 15 gray wolves from eleven genetically distinct populations worldwide (including Europe, Asia and America), one red wolf (C. rufus), one coyote (C. latrans) and one golden jackal (C. aureus). This expanded dataset of wolf-like canids, combined with a probe density higher than in previous studies, allowed us to perform the first high resolution characterization of $\mathrm{CNVs}$ in wolf-like canids and identify CNV break points over at a longer time-scale.

\section{Results and discussion}

\section{Distribution and genomic effects of CNVs}

To investigate CNVs in wolf-like canids we genotyped 23 canids (4 purebred dogs, one dingo, 15 gray wolves, one red wolf, one coyote and one golden jackal) for 1,611 CNVs previously typed in 61 dogs by Nicholas et al. [20] who compiled all the CNVs previously reported, mainly in modern dog breeds [18,19] (Additional file 1: Table S1). We assessed the performance of our $\mathrm{CNV}$ genotyping using a two-stage procedure. In a first discovery stage, we identified CNVs using a conservative approach based on the combination on two methods: a Reversible Jump hidden Markov Model [26] and the procedure described in [21]. In the second stage, we genotyped our samples for each of these discovered CNV regions (see Methods).

We used three approaches to estimate false discovery rate and assess data quality. First, we performed two self-self hybridizations with a Boxer (the reference genome in our study) and a wolf from Iran. This analysis called only 12 and $11 \mathrm{CNVs}$, respectively, suggesting a low false discovery rate similar to that obtained by [20]. Second, we included 42 putative single copy control regions used by Nicholas et al. [20] on the aCGH chip. Across 966 control regions analyzed (42 regions $\times 23$ samples), our algorithm only called $17 \mathrm{CNVs}$, suggesting a lower false discovery rate $(1.75 \%)$ than obtained by [20]. Third, quantitative PCR (qPCR) was perfomed using Taqman assays on 10 canids (included the Boxer used in the aCGH experiments as a reference) to further validate $3 \mathrm{CNV}$ regions (see Methods). In all the cases the $\mathrm{qPCR}$ validate the $\mathrm{CNV}$ regions. Assuming the $\mathrm{qPCR}$ results represent the correct copy number of individuals, we estimate a false positive rate of 0 and a false negative rate of $17.66 \%$ in the calling in the aCGH data, confirming the conservativeness of threshold for calling CNVs in the aCGH data.

We found a total of $860 \mathrm{CNVs}$ distributed in 715 of the 1,611 regions analyzed (Figure 1 , Table 1 , Additional file 2: Table S2). Many of the regions analyzed (55.6\%) did not show any CNV in our dataset probably due to several reasons. First, not all the previously reported CNVs had the same level of support. In fact, only $31.28 \%$ of the original 1,611 regions previously analyzed were labeled as "high confidence CNVs" (as reported in [20]) and we found CNVs in our dataset in almost 75\% of these regions. Second, the design of the array was based almost exclusively on modern dog breeds (26 dogs from 21 breeds and only one wolf) and a high proportion of the CNVs were identified in just one individual each (32\% in [19] and $64.5 \%$ in [20]). Since we only genotyped 4 purebred dogs, many of these CNVs may not have been detectable.

Of the 860 CNVs regions that we identified, 412 (47.9\%) were shared between dogs and wild canids. Dogspecific CNVs were $12.3 \%$ (106 CNVs) of the total but the design of the array and the different number of samples analyzed (5 vs 18) suggests this was an underestimation (Figure 1). These 106 derived CNVs may have originated after domestication but most of them (78.3\%) were present in only one dog, so likely arose later in the evolutionary history of dogs. Selection could have fixed some of these variants in some breeds or alternatively, given the small effective population size of breeds, 


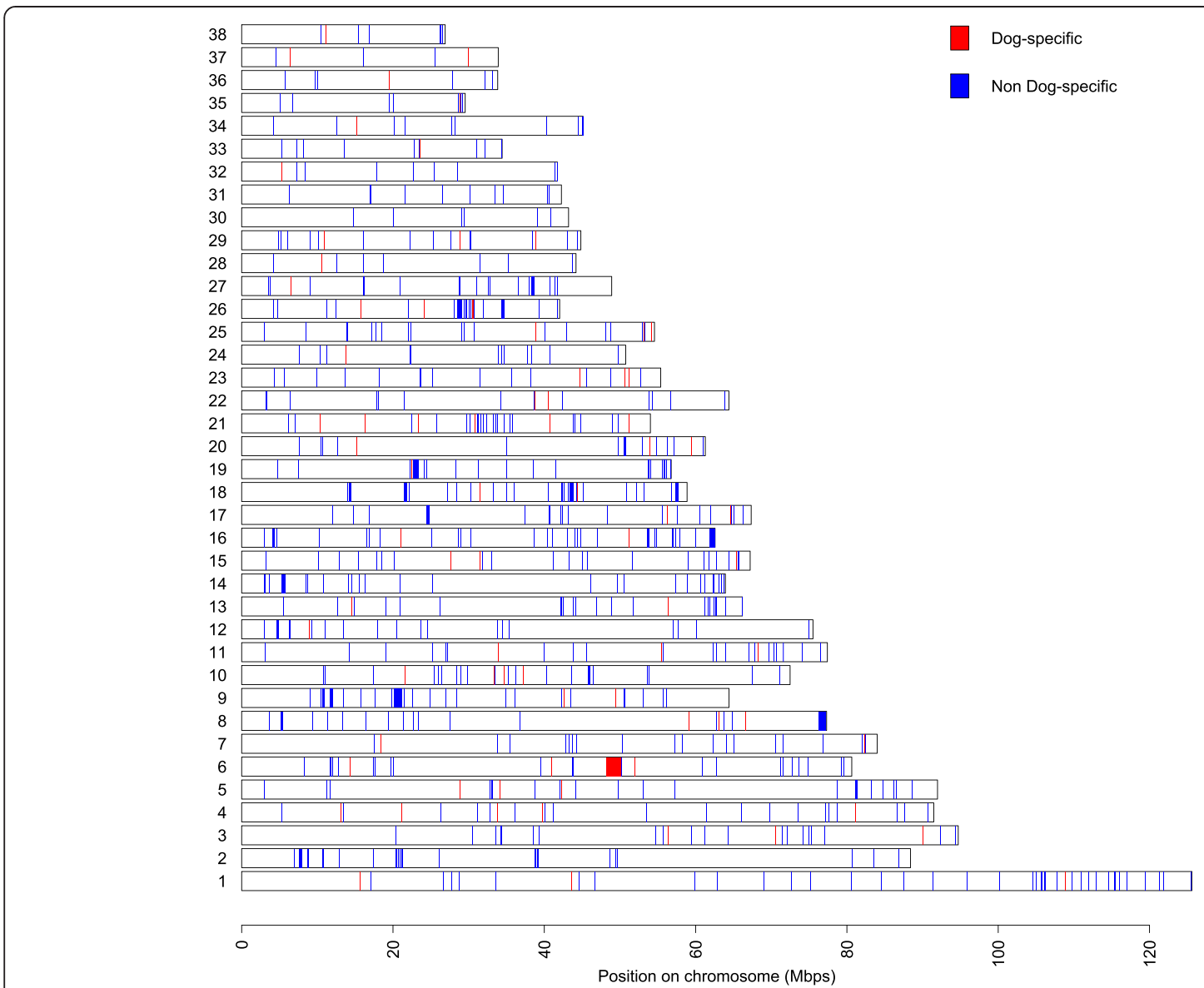

Figure 1 Chromosomal distribution of $\mathbf{8 6 0}$ CNVs in the canine genome. The chromosomes are represented by bars; colors indicate the location of the 860 CNVs. Red marks indicate dog-specific CNVs.

strong genetic drift and founder effect might have overcome the possible negative effects of CNVs. Consequently, we analyzed whether these $106 \mathrm{CNVs}$ were enriched for genes, compared to the 754 non-dogspecific regions (860-106) or to the total 1,611 regions (see Methods). Although not all intergenic variants may be neutral (for example, by influencing the expression levels of nearby genes [27]), our randomization test suggested that those $106 \mathrm{CNVs}$ might not be under strong selection since we did not find any enrichment in the number of genes in dog specific regions compared to non-dog-specific regions $(P$-value $=0.744)$ or the total 1,611 regions $(P=0.844)$ (Additional file 1: Figure S1). Similarly, no gene ontology category was overrepresented in dog-specific or in the whole set of $1,611 \mathrm{CNV}$ regions.

In relation to overall $\mathrm{CNV}$ diversity, the sample with lowest CNVs identified was the Boxer, probably because the reference was also a Boxer. In the same way, we also found more CNVs in wolves than in dogs (Table 1). In order to quantify the differences between dogs and wolves, we calculated allele frequencies for each $\mathrm{CNV}$ in dogs and wolves using the EM algorithm [28]. From these allele frequencies, we estimated the expected heterozygosity $\left(\mathrm{H}_{\mathrm{e}}\right)$ for each polymorphic $\mathrm{CNV}$ and the average for dogs and gray wolves. Since the number of wolf samples analyzed was higher (15 gray wolves vs 5 purebred plus dingo), we estimated the random expectation averaging $\mathrm{H}_{\mathrm{e}}$ for 1,000 groups of 5 randomly selected gray wolves and found that the structural variability in dogs and gray wolves are very similar (0.299 \pm 0.009 for wolves vs 0.305 for dogs, $P=0.235$ ). Domestication is associated with a very large reduction in the population size in dogs (16-fold compared to a much smaller 3-fold reduction in wolves; [29]). However, we do not see a similar reduction of CNV variation in dogs in our aCGH data, most likely because of the ascertainment bias in the design of the array, which is expected to result in higher levels of $\mathrm{CNV}$ variation in dogs.

In agreement with previous studies [18-21,30,31], we found more losses than gains both in dogs and wolves. This is partly attributable to technical biases, because in aCGH experiments copy gains are more difficult to genotype than losses [21]. Since in aCGH experiments 
Table 1 Summary of CNVs genotyped per sample

\begin{tabular}{|c|c|c|c|c|c|c|}
\hline \multirow[t]{2}{*}{ Sample } & \multicolumn{3}{|c|}{ Total CNVs } & \multicolumn{3}{|c|}{ Unique CNVs* } \\
\hline & Total & Gains & Loses & Total & Gains & Loses \\
\hline Boxer & 153 & 88 & 65 & 19 & 8 & 11 \\
\hline Dachshund & 218 & 92 & 126 & 7 & 2 & 5 \\
\hline Beagle & 209 & 89 & 120 & 16 & 7 & 9 \\
\hline Basenji & 267 & 90 & 177 & 32 & 8 & 24 \\
\hline Dingo & 186 & 56 & 130 & 8 & 0 & 8 \\
\hline IsraelWolf & 252 & 128 & 124 & 3 & 0 & 3 \\
\hline IsraelWolf2 & 194 & 75 & 119 & 2 & 0 & 2 \\
\hline ItalianWolf & 224 & 100 & 124 & 0 & 0 & 0 \\
\hline ItalianWolf2 & 185 & 89 & 96 & 2 & 0 & 2 \\
\hline PortugueseWolf & 202 & 77 & 125 & 5 & 2 & 3 \\
\hline IberianWolf & 211 & 95 & 116 & 6 & 4 & 2 \\
\hline YellowstoneWolf & 270 & 79 & 191 & 34 & 2 & 32 \\
\hline GreatlakesWolf & 268 & 148 & 120 & 12 & 10 & 2 \\
\hline IranianWolf & 209 & 80 & 129 & 0 & 0 & 0 \\
\hline MexicanWolf & 211 & 93 & 118 & 2 & 0 & 2 \\
\hline ChineseWolf & 181 & 73 & 108 & 0 & 0 & 0 \\
\hline IndianWolf & 226 & 87 & 139 & 9 & 4 & 5 \\
\hline MongolianWolf & 162 & 71 & 91 & 0 & 0 & 0 \\
\hline MongolianWolf2 & 265 & 136 & 129 & 14 & 9 & 5 \\
\hline SwedenWolf & 224 & 94 & 130 & 10 & 7 & 3 \\
\hline RedWolf & 223 & 123 & 100 & 8 & 6 & 2 \\
\hline Coyote & 200 & 94 & 106 & 4 & 1 & 3 \\
\hline Golden Jackal & 215 & 103 & 112 & 22 & 4 & 18 \\
\hline
\end{tabular}

*Unique are defined as CNV that are present only in one sample.

losses and gains are relative to the reference genome it is not possible to separate duplications and deletions without an outgroup. We used data from wolf-like canids to determine the ancestral state and thus identify duplications and deletion in dogs. We considered a postdomestication CNV event any gain or loss present in dogs but not in any wolves. We found 190 and 150 postdomestication duplications and deletions, respectively. It has been suggested that gene deletions are more likely to be deleterious than duplications and therefore more likely to be purged by purifying selection. However, we did not find an enrichment in genes in the 190 regions with duplications in dogs compared to the whole set of 1,611 CNV regions $(P=0.519)$, while we found gene enrichment in the 150 regions with deletions $(P<0.001$; Additional file 1: Figure S2) suggesting a potential relaxation of purifying selection in dogs. This is consistent with previous studies which have described a relative increase in the proportion of non synonymous substitutions in the dog genome, suggested to be the result of a relaxation of the purifying selection in dogs $[8,32]$. This could be due to changes in the way of life of dogs and, specially, to the reduction of their effective population size compared to the population size of the ancestor species, the gray wolf, during domestication.

\section{Analysis of CNV breakpoints}

Taking advantage of our higher aCGH resolution, we could define CNV breakpoints within 400 bp and analyze their nucleotide composition. GC-peaks were defined as $500 \mathrm{bp}$ windows or greater centered in $10 \mathrm{~kb}$ windows with more than $50 \%$ increase in GC-content [21]. We found an even clearer enrichment of peaks of GC-high regions close to the breakpoints compared to previous results [21]. The enrichment rapidly decays outside breakpoints (steps of $400 \mathrm{bp}$ ) (Additional file 1: Figure S3). We next recorded the nucleotide fine-scale GC-content around the breakpoints in sliding windows of $400 \mathrm{bp}$ (Figure 2). We found a small increase in GCcontent about a kb outside the breakpoint, although there seemed to be a small local decrease in GC-content exactly at the breakpoint. However, our ability to locate the exact position of the breakpoints fluctuated over a few hundred bp given the probe distribution in the arrays (repeats, which are enriched in breakpoints are not covered by probes) and the CNV callers tended to have some uncertainty in the transition probes at the breakpoints. Assuming some uncertainties in the identification of the breakpoints, we still found local peaks around $1 \mathrm{~kb}$ from the breakpoint that could indicate some common motif, whereas the observed increase in $\mathrm{GC}$-content within the CNVs could indicate the effects of biased gene conversion which increases GC-content in duplicated sequences.

We next searched for stretches of perfect homology between breakpoint pairs defined using the $400 \mathrm{bp}$ windows. The longest stretch of perfect homology was recorded for paired breakpoints. The mean length was $10.9 \mathrm{bp}$. The pairs were then randomly redistributed on the same chromosome to evaluate statistical significance, with a mean of $9.2 \mathrm{bp}$ using a Wilcoxon rank sum test. We found a small but significant increase in homology between breakpoint pairs compared to a random expectation, supporting NAHR as a main mechanism for formation of CNVs in canids. An even stronger effect is supported when increasing the breakpoint size to $2 \mathrm{~kb}$ to include the peculiar GC-pattern seen one $\mathrm{kb}$ away from the break; the homology stretch then increased to 22.8 bp vs. 14.2 bp expected by chance $(P<0.001$, Wilcoxon rank sum test).

We finally searched for regions of overlap between breakpoint windows and repeats using the RepeatMasker Track. The repeat families Simple repeats and L1 repeats were enriched in breakpoint windows $(P<0.01$, random resampling). When we divided L1 repeats according to their age, recent L1s were more enriched than older 

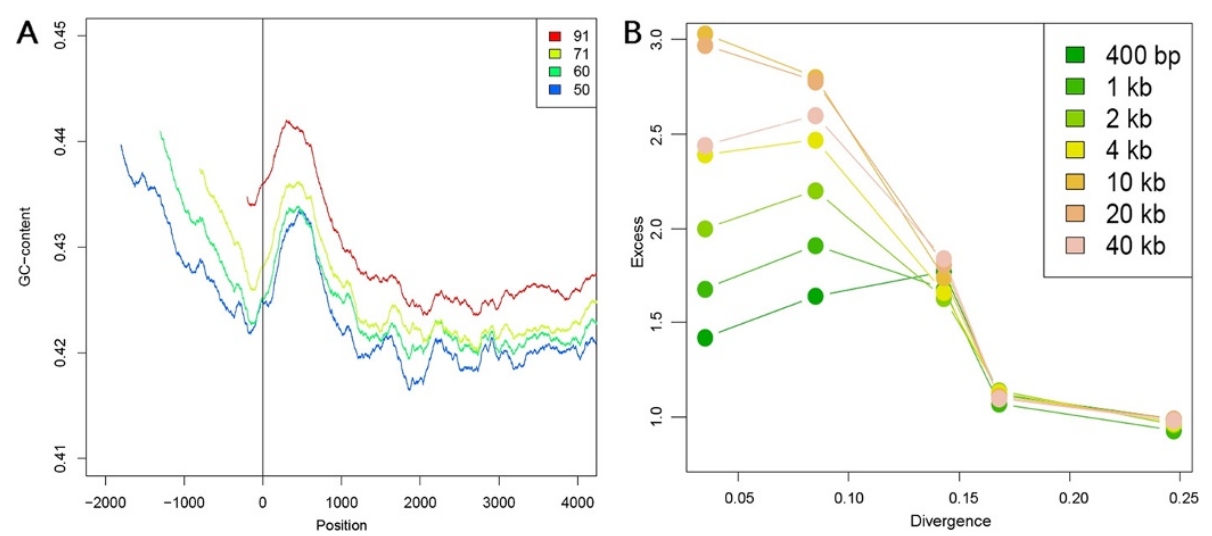

Figure 2 CNV breakpoints composition analysis. A: Base composition of CNV breakpoints. GC-content in 400 bp windows around the breakpoint recorded at the center of each window. Negative locations represent windows inside the CNVs and colors represent the proportion of CNVs with a size that can cover a window at a specific distance inside the CNVs. B: Enrichment of L1 repeats in CNV breakpoints. Observed to expected ratios of 5 classes of differentially diverged L1 repeats in CNV breakpoints. Colors represent the size of the CNV breakpoint.

ones (Figure 2), although not as pronounced as previously observed (20). Statistical enrichment of L1 repeats varied with breakpoint size in a fashion where enrichment increased with window sizes up to $10 \mathrm{~kb}$ and slowly decreased with larger window sizes. Therefore CNV breakpoints tend to have young L1 repeats nearby, although they are not overlapping.

\section{Candidate CNV selected during dog domestication}

Regions under selection early in dog domestication should be highly differentiated from those in the gray wolf, whereas regions selected during breed formation should show differentiation signals between dog breeds. Previous studies have focused on these later regions. To select the most differentiated regions between dog (including the dingo) and wild canids we calculated $V_{\mathrm{ST}}$ for each polymorphic region as previously described [30]. The distribution of $V_{\mathrm{ST}}$ showed that most of the regions $(84.4 \%)$ had low $(<0.1) \quad V_{\mathrm{ST}}$ (Figure 3 ), and the average $V_{\mathrm{ST}}(0.054)$ was lower than the $F_{\mathrm{ST}}$ obtained from SNP data [10]. Similarly, the estimates of $F_{\mathrm{ST}}$ for purebred dogs obtained from $\mathrm{CNV}$ data were also lower than the estimates obtained from SNP data [20]. This low estimate could be due to the smaller number of samples analyzed. However, we found regions with an estimate of $V_{\mathrm{ST}}$ several-fold higher than the average. For instance, within the 25 most differentiated regions, the lowest $V_{\mathrm{ST}}$ is 0.226 (>average $V_{\mathrm{ST}}+2.5 \mathrm{SD}$ ) and the average $V_{\mathrm{ST}}$ is 0.319 .

Of the 12 candidate genes in the most differentiated regions (Table 2), three genes are related to growth (PDE4D, CRTC3 and NEB). The CNVs that include the CRTC3 gene have higher copy number in dogs (with the exception of the dingo) than in gray wolves. It has been shown that $C R T C 3^{-/-m}$ ice maintained on a normal chow diet appear more insulin-sensitive than controls and also have $50 \%$ lower adipose tissue mass than control mice despite comparable physical activity [33].

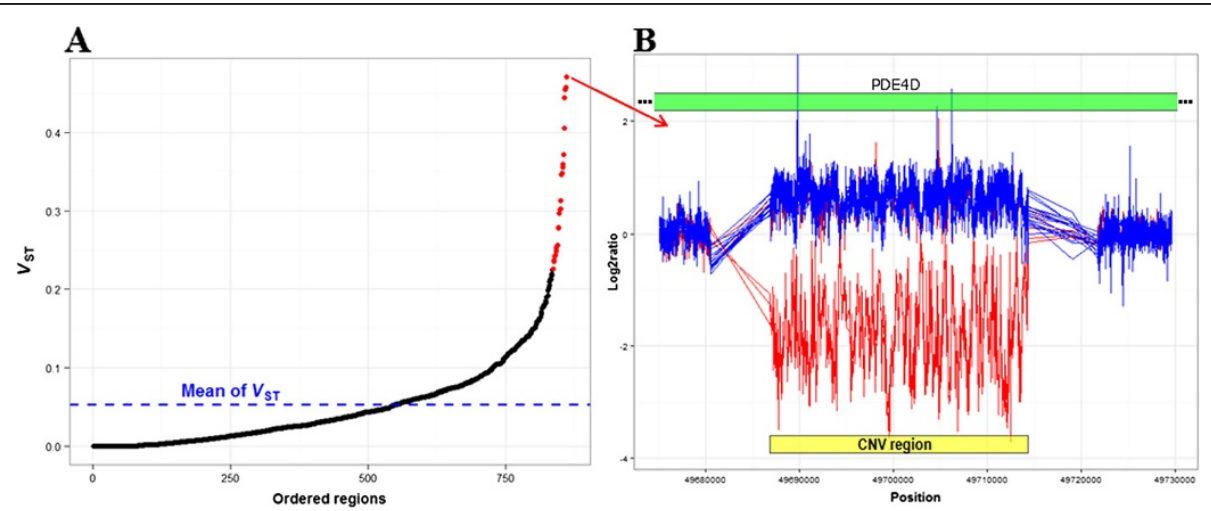

Figure 3 Candidate CNVs selected during dog domestication. A: Values of $V_{S T}$ between dogs and wolves for the 860 regions (ordered by the $V_{\text {ST }}$ value). In red, the 25 regions with highest $V_{\text {ST }}$ values. B: Log2values of the region with highest $V_{\text {ST; }}$ dogs are represented in red. The CNV region (yellow) overlaps with the PDE4D gene (green). 
Table 2 List of top $\mathbf{2 5}$ most differentiated regions based on $V_{\mathrm{ST}}$ between dog and wild canids

\begin{tabular}{|c|c|c|c|c|}
\hline$V_{S T}$ & Chr & Start & End & Gene \\
\hline 0.470 & chr2 & $49,686,866$ & $49,714,373$ & $\begin{array}{l}\text { Phosphodiesterase 4D, } \\
\text { cAMP-specific (PDE4D) }\end{array}$ \\
\hline 0.458 & chr8 & $63,053,405$ & $63,054,226$ & $\begin{array}{l}\text { Echinoderm microtubule } \\
\text { associated protein like } 5(E M L 5)\end{array}$ \\
\hline 0.455 & chr9 & $20,104,325$ & $20,942,683$ & \\
\hline 0.444 & chr34 & $15,222,600$ & $15,228,141$ & \\
\hline 0.405 & chr3 & $56,422,480$ & $56,425,666$ & $\begin{array}{l}\text { CREB regulated transcription } \\
\text { coactivator } 3(C R T C 3)\end{array}$ \\
\hline 0.372 & chr18 & $57,419,688$ & $57,432,938$ & \\
\hline 0.360 & chr10 & $11,064,284$ & $11,065,425$ & \\
\hline 0.356 & chr10 & $37,202,529$ & $37,206,649$ & \\
\hline 0.348 & chr6 & $40,916,498$ & $40,919,469$ & $\begin{array}{l}\text { Zinc finger protein } \\
500 \text { (ZNF500) }\end{array}$ \\
\hline 0.346 & chr8 & $19,445,383$ & $19,454,376$ & \\
\hline 0.313 & chr28 & $35,223,479$ & $35,250,497$ & $\begin{array}{l}\text { Deleted in malignant brain } \\
\text { tumors } 1 \text { (DMBT1) }\end{array}$ \\
\hline 0.303 & chr26 & $15,768,680$ & $15,778,843$ & \\
\hline 0.301 & chr20 & $10,484,859$ & $10,488,574$ & $\begin{array}{l}\text { Solute carrier family } 6 \\
\text { (neurotransmitter transporter), } \\
\text { member } 11(\text { SLC6A11) }\end{array}$ \\
\hline 0.297 & chr10 & $21,640,830$ & $21,644,386$ & \\
\hline 0.279 & chr7 & $35,432,582$ & $35,437,565$ & $\begin{array}{l}\text { Regulator of G-protein } \\
\text { signaling } 7 \text { (RGS7) }\end{array}$ \\
\hline 0.278 & chr22 & $34,304,138$ & $34,305,222$ & $\begin{array}{l}\text { EDNRB antisense RNA } 1 \\
\text { (EDNRB-AS1) }\end{array}$ \\
\hline 0.257 & chr28 & $16,096,188$ & $16,106,945$ & \\
\hline 0.255 & chr5 & $38,737,275$ & $38,738,036$ & $\begin{array}{l}\text { Dynein, axonemal, } \\
\text { heavy chain } 9 \text { (DNAH9) }\end{array}$ \\
\hline 0.253 & chr6 & $50,243,863$ & $50,244,363$ & \\
\hline 0.249 & chr26 & $31,903,962$ & $31,981,330$ & \\
\hline 0.244 & chr14 & $3,093,975$ & $3,101,514$ & \\
\hline 0.243 & chr8 & $11,405,495$ & $11,411,624$ & \\
\hline 0.237 & chr11 & $45,618,474$ & $45,621,740$ & $\begin{array}{l}\text { ELAV like neuron-specific RNA } \\
\text { binding protein } 2 \text { (ELAVL2) }\end{array}$ \\
\hline 0.236 & chr1 & $15,627,405$ & $15,636,380$ & \\
\hline 0.226 & chr26 & $34,271,837$ & $34,692,378$ & $\begin{array}{l}\text { Topoisomerase (DNA) III beta } \\
\text { (TOP3B)/Nebulin (NEB) }\end{array}$ \\
\hline
\end{tabular}

Incidence of overweight and obesity in dogs exceeds $30 \%$, and several breeds are predisposed to this heritable phenotype [34]. However, perhaps the most striking example of potential divergence in function is for the $P D E 4 D$ gene (Figure 3). For this region, all wild canids present the same genotype (gain), whereas most of the studied dogs (Boxer, Beagle and Basenji) present losses. Mice that are deficient in this isoenzyme exhibit delayed growth with a $30-40 \%$ decrease in body weight at 1-2 weeks after birth [35]. Although growth rate returned to normal after 2 weeks, the weight of the adult mice remained lower than normal due to a decrease in muscle and bone mass and internal organ weight (with the exception of cortex and cerebellum) associated with a decrease in circulating insulin-like growth factor I (IGF1) levels. The IGF1 gene is a strong genetic determinant of body size across mammals and a single IGF1 allele is a major determinant of small size in dogs [1]. Consequently, CNVs near these genes may affect gene expression of this body size associated gene, or act as tag for sequence changes in the gene or its promoter that affect expression. In dogs, six genes explain $\sim 50 \%$ of standard breed weight and it is hypothesized that these largeeffect variants are superimposed on a subtler sizeregulation system inherited from wolves [36]. Wolves vary substantially in size, with weights ranging from 16 to $60 \mathrm{~kg}$ in Europe alone [37]. On the other hand, PDE4 inhibitors also facilitate hippocampal long-term potentiation in addition to improving cognitive performance in multiple animal models and reverse memory impairments in genetic mouse models of human disorders [38]. In particular, $P D E 4 D^{-/-}$mice exhibited enhanced earlylong-term potentiation following multiple induction protocols [38].

Interestingly, among the 12 candidate genes, six other genes also are implicated in neurological function in other mammalian species (EML5, ZNF500, SLC6A11, ELAVL2, RGS7 and TOP3B) [39-45]. The synaptic regulator SLC6A11 is a particularly interesting candidate since human genetic studies indicate that a CNV including this gene is associated with autism spectrum disorders and schizophrenia [41]. One of the most unique behavioral traits of dogs relative to wolves is their socialcommunicative skills with humans. Domestic dogs are more skillful than chimpanzees and wolves at using human social clues to find hidden food in the object choice paradigm [46-48]. This trait likely enabled domestication and facilitated the rapid evolution of genes expressed in the brains of dogs $[9,49]$.

It is relevant that, among the 12 genes within highly differentiated $\mathrm{CNV}$ regions between dog and wolf 9 of them are related to two functions, typically associated with the process of domestication. However, further functional studies are needed to disentangle the complete role of these genes in the dog domestication process.

\section{Conclusions}

In this study, we make use of previously reported CNVs in modern dog breeds to explore the evolutionary origin of these sites by using a novel panel of wolf-like canids.

This expanded dataset, combined with our customdesigned higher density array, allowing us to determine the ancestral state and polarize the process of CNV formation in dogs. We identified some candidate genes within $\mathrm{CNV}$ regions that are highly differentiated 
between dogs and wolves, which provide insights into the role of structural variation in the process of dog domestication and in diversification of phenotypes observed among dog breeds. In general our results add significantly to resolution of structural variation and breakpoints in canids. However, ascertainment bias is a problem for the interpretation of CNV patterns in wild canids and analyses of CNVs based on whole genome sequencing will be highly beneficial to evaluate the evolution and impact of structural variability in the process of domestication.

\section{Methods}

\section{DNA samples}

A female Boxer (distinct from Tasha, used by Nicholas et al. [19,20] and whose genome was sequenced [14]) was used as reference in all the aCGH hybridizations. The samples used for the aCGH experiments corresponded to four purebred dogs (from four breeds: Boxer, Dachshund, Beagle and Basenji), one Dingo, 15 gray wolves, one red wolf, one coyote and one golden jackal. The origin of these wolf samples covers a large geographic range, including European, American and Asian populations (Table 1). All wolf samples derive from animals killed or found dead for reasons other than this research and deposited in scientific collections. Dog samples derive from veterinary clinics and were obtained with the permission of the owner. A total of two self-self hybridizations were done using a Boxer and an Iranian wolf. DNA quality of all samples was assessed by taking OD260/280 and OD260/230 readings using a nanospectrometer and agarose gel electrophoresis. Hybridizations of genomic DNA to NimbleGen aCGH chip were performed in the Genomics Core Facility of the Centre for Genomic Regulation (CRG) in Barcelona (Spain).

\section{Array design}

A NimbleGen aCGH chip was designed to sample the same regions covered in [20], but with higher density. Specifically, the mean probe space varied depending on the length of the tiled region. For regions smaller than $100 \mathrm{~kb}$ (93\% of the regions), the mean probe space was $50 \mathrm{bp}$; for regions between 100 and $300 \mathrm{~kb}$ (5\%), probes were separated by $150 \mathrm{bp}$ on average and finally, for regions longer than $300 \mathrm{~kb}(2 \%)$, mean probe spacing was $1 \mathrm{~kb}$. Furthermore, 42 putative control regions were included in the chip. Overall, the chip contains 598,733 probes with an average probe spacing of $157 \mathrm{bp}$.

\section{Validation of CNV regions by $\mathrm{qPCR}$}

We performed qPCR on 4 dogs (included the Boxer), 3 wolves, 1 coyote and 2 jackals from $3 \mathrm{CNV}$ regions that involve PDE4D, CRTC3 and SLC6A11 genes, all of them present in Table 2.
Estimation of copy number was performed using a Multiplex TaqMan assays. Each duplex reaction contained TaqMan probes and primers to amplify C7orf28B [6], which is known to exist in two copies in a canid genome (900 nM of forward and reverse primers, 250 nM VIC and TAMRA labeled probe, Applied Biosystems), and the TaqMan probes and primers (Additional file 1: Table S3) used to amplify the test regions (300 nM of forward and reverse primers, $250 \mathrm{nM}$ FAM labeled MGB probe, Applied Biosystems). Amplicons were done in genomic DNA under the following conditions: one cycle at $50^{\circ} \mathrm{C}$ for $2 \mathrm{~min}$, one cycle at $95^{\circ} \mathrm{C}$ for $10 \mathrm{~min}$ and 40 cycles at $95^{\circ} \mathrm{C}$ for $15 \mathrm{sec}, 55^{\circ} \mathrm{C}$ for $30 \mathrm{sec}$ and $72^{\circ} \mathrm{C}$ for $30 \mathrm{sec}$. Three replicates were performed for each sample.

\section{CNV genotyping}

We first identified CNV regions in each sample using two methods: a Reversible Jump hidden Markov Model implemented in the software RJaCGH [26] and the procedure described in [21]. For the first method, we required an average posterior probability of the probes in the putative CNV greater than 0.60 if the segment consisted of at least 50 probes and greater than 0.75 if the segment had between 30 and 49 probes. We discarded segments with less than 30 probes. Then, for each sample we joined $\mathrm{CNV}$ regions if they fulfilled at least one of the following conditions: they were less than $3 \mathrm{~kb}$ apart from each other or the region between them had more than $80 \%$ repeats or gaps (downloaded from the UCSC Table Browser). Next, overlapping CNV regions were merged across all the samples in order to define a set of 860 regions that were used for the genotyping step.

In the genotyping step, we genotyped each sample in the 860 regions previously identified, requiring an average $\log _{2}$ value of the region equal to the median \pm 1.5 * standard deviation of all $\log _{2}$ values of the chip.

\section{Statistical and population genetics analysis}

Genotypes were simplified into 3 categories: equal copy, gain and loss, and allele frequencies for each category were estimated using a simple EM algorithm. These allele frequencies were used to calculate expected heterozygosity in each of the 860 regions for dogs and wolves as $\mathrm{He}=1-\left(\mathrm{p}^{2}+\mathrm{q}^{2}+\mathrm{r}^{2}\right)$, where $\mathrm{p}, \mathrm{q}$, and $\mathrm{r}$ indicate the frequencies of samples carrying normal copy, gains, and losses, respectively. Furthermore, we computed $V_{\mathrm{ST}}$ for each CNV region as: $V_{\mathrm{ST}}=\left(V_{\mathrm{T}}-V_{\mathrm{S}}\right) / V_{\mathrm{T}}$, where $V_{\mathrm{T}}$ is the variance in $\log _{2}$ ratios among all unrelated individuals and $V_{\mathrm{S}}$ is the average variance within each population, weighted for population size. 


\section{Candidate genes}

We downloaded a complete list of all canine genes from Ensemble, which comprised 24,580 genes in CanFam3.1 coordinates.

In order to determine the genes that a given set of $\mathrm{CNV}$ regions contain or overlapped, we first used liftOver (http://genome.ucsc.edu/cgi-bin/hgLiftOver) to map the coordinates of the regions of interest to CanFam3.1 coordinates. Then, we intersected those coordinates with the gene list.

The list of genes was analyzed with PANTHER (Protein ANalysisTHrough Evolutionary Relationships) [50] using default options. PANTHER provides a functional analysis combining GO.

Next, to investigate whether a given set of $\mathrm{CNV}$ regions was significantly enriched or depleted in genes, 1,000 sets with the same number and length of regions were simulated across either the 1,611 regions analyzed or the 754 non dog specific regions. The number of genes for each of the simulated sets was calculated, and compared with the original set to obtain statistical significance.

\section{Analyses on the breakpoints}

Breakpoints were defined as windows of $400 \mathrm{bp}$, the smallest size of any detected CNV, surrounding the inferred breakpoint position to account for the imprecision in determining the exact location.

Peaks of elevated GC-content were defined as in [21], with a 500 bp peak discovery window centered in a 10 kb background window. To record peaks, these two windows were simultaneously slid along the genome to detect increased levels of GC-content of $50 \%$ in the peak window relative to the background window.

Analyses of enrichment and overlap between genomic features were done chromosome-wise by repeatedly and randomly redistributing the regions to estimate sample means to infer statistical significance. The two breakpoints of a CNV were kept at the same distance from each other during the process.

Repeat locations came from the RepeatMasker track of the UCSC genome browser (genome.ucsc.edu). L1 repeats were divided according to their age (origin from Canisfamiliaris, Canis, Canidae, Carnivora, older Mammalia/Eutheria) using Repbase (www.girinst.org/repbase/).

\section{Additional files}

Additional file 1: File containing Table S1, and S3, Figure S1, S2, S3 and their legends.

Additional file 2: Excel file containing Table S2.

\section{Competing interests}

The authors declare that they have no competing interests.
Authors' contributions

OR, MTW, RKW, CL-F, CV and TM-B contributed to the design of this research. $\mathrm{OR}, \mathrm{JH}-\mathrm{R}$ and $\mathrm{IO}$ performed the experimental analyses. OR, IO, JB, BLG and JQ performed the data analysis. OR, IO and TM-B wrote the manuscript. All authors read and approved the final manuscript.

\section{Acknowledgements}

We are grateful to Thomas J Nicholas and Joshua M Akey for access to some dog samples previously analyzed by them. OR is a postdoctoral Researcher from the JAEdoc program cofounded by European Science Foundation. IO has a predoctoral fellowship from the Basque Government (DEUI). This work has been founded by Spanish Government Grants BFU2011-28549 (to TM-B) and BFU2012-34157 (to CL-F), Andalusian Government Grant "Programa de Captación del Conocimiento para Andalucía C2A" (to CV) and EU ERC Starting Grant 260372 (to TM-B).

\section{Data release}

All aCGH data has been submitted to Gene Expression Omnibus (GEO; http://www.ncbi.nlm.nih.gov/geo/info/linking.html) under the accession number GSE58195.

\section{Author details}

${ }^{1}$ Institut de Biologia Evolutiva (Universitat Pompeu Fabra - CSIC),

Ciències Experimentals i de la Salut, Barcelona 08003, Spain. ²Department of Medical Biochemistry and Microbiology, Science for Life Laboratory, Uppsala University, Uppsala 75123, Sweden. ${ }^{3}$ UCLA, Department of Ecology and Evolutionary Biology, Los Angeles 90095, CA, USA. ${ }^{4}$ Estación Biológica de Doñana EBD-CSIC, Conservation and Evolutionary Genetics Group, Sevilla 41092, Spain. ${ }^{5}$ Institució Catalana de Recerca i Estudis Avançats (ICREA), Barcelona, Spain. ${ }^{6}$ Centro Nacional de Análisi Genómico (CNAG), Barcelona 08028, Spain.

Received: 14 May 2014 Accepted: 6 June 2014

Published: 12 June 2014

\section{References}

1. Sutter NB, Bustamante CD, Chase K, Gray MM, Zhao K, Zhu L, Padhukasahasram B, Karlins E, Davis S, Jones PG, Quignon P, Johnson GS, Parker HG, Fretwell N, Mosher DS, Lawler DF, Satyaraj E, Nordborg M, Lark KG, Wayne RK, Ostrander EA: A single IGF1 allele is a major determinant of small size in dogs. Science 2007, 316:112-115.

2. Akey JM, Ruhe AL, Akey DT, Wong AK, Connelly CF, Madeoy J, Nicholas TJ, Neff MW: Tracking footprints of artificial selection in the dog genome. Proc Natl Acad Sci U S A 2010, 107:1160-1165.

3. Boyko AR, Quignon P, Li L, Schoenebeck JJ, Degenhardt JD, Lohmueller KE, Zhao K, Brisbin A, Parker HG, von Holdt BM, Cargill M, Auton A, Reynolds A Elkahloun AG, Castelhano M, Mosher DS, Sutter NB, Johnson GS, Novembre J, Hubisz MJ, Siepel A, Wayne RK, Bustamante CD, Ostrander EA: A simple genetic architecture underlies morphological variation in dogs. PLOS Biol 2010, 8:e1000451.

4. Wayne RK, von Holdt BM: Evolutionary genomics of dog domestication. Mamm Genome 2012, 23:3-18.

5. Vaysse A, Ratnakumar A, Derrien T, Axelsson E, Rosengren Pielberg G, Sigurdsson S, Fall T, Seppälä EH, Hansen MST, Lawley CT, Karlsson EK, Bannasch D, Vilà C, Lohi H, Galibert F, Fredholm M, Häggström J, Hedhammar A, André C, Lindblad-Toh K, Hitte C, Webster MT: Identification of genomic regions associated with phenotypic variation between dog breeds using selection mapping. PLOS Genet 2011, 7:e1002316.

6. Axelsson E, Ratnakumar A, Arendt M-L, Maqbool K, Webster MT, Perloski M, Liberg O, Arnemo JM, Hedhammar A, Lindblad-Toh K: The genomic signature of dog domestication reveals adaptation to a starch-rich diet. Nature 2013, 495:360-364.

7. Vonholdt BM, Pollinger JP, Lohmueller KE, Han E, Parker HG, Quignon P, Degenhardt JD, Boyko AR, Earl DA, Auton A, Reynolds A, Bryc K, Brisbin A, Knowles JC, Mosher DS, Spady TC, Elkahloun A, Geffen E, Pilot M, Jedrzejewski W, Greco C, Randi E, Bannasch D, Wilton A, Shearman J, Musiani M, Cargill M, Jones PG, Qian Z, Huang W, et al: Genome-wide SNP and haplotype analyses reveal a rich history underlying dog domestication. Nature 2010, 464:898-902. 
8. Cruz F, Vilà C, Webster MT: The legacy of domestication: accumulation of deleterious mutations in the dog genome. Mol Biol Evol 2008, 25:2331-2336

9. Saetre P, Lindberg J, Leonard JA, Olsson K, Pettersson U, Ellegren $\mathrm{H}$, Bergström TF, Vilà C, Jazin E: From wild wolf to domestic dog: gene expression changes in the brain. Brain Res Mol Brain Res 2004, 126:198-206.

10. VonHoldt BM, Pollinger JP, Earl DA, Knowles JC, Boyko AR, Parker H, Geffen E, Pilot M, Jedrzejewski W, Jedrzejewska B, Sidorovich V, Greco C, Randi E, Musiani M, Kays R, Bustamante CD, Ostrander EA, Novembre J, Wayne RK: A genome-wide perspective on the evolutionary history of enigmatic wolf-like canids. Genome Res 2011, 21:1294-1305.

11. Vilà C, Seddon J, Ellegren H: Genes of domestic mammals augmented by backcrossing with wild ancestors. Trends Genet 2005, 21:214-218.

12. Boyko AR, Boyko RH, Boyko CM, Parker HG, Castelhano M, Corey L, Degenhardt JD, Auton A, Hedimbi M, Kityo R, Ostrander EA, Schoenebeck J, Todhunter RJ, Jones P, Bustamante CD: Complex population structure in African village dogs and its implications for inferring dog domestication history. Proc Natl Acad Sci U S A 2009, 106:13903-13908.

13. Parker HG, Kim LV, Sutter NB, Carlson S, Lorentzen TD, Malek TB, Johnson GS, DeFrance HB, Ostrander EA, Kruglyak L: Genetic structure of the purebred domestic dog. Science 2004, 304:1160-1164.

14. Lindblad-Toh K, Wade CM, Mikkelsen TS, Karlsson EK, Jaffe DB, Kamal M, Clamp M, Chang JL, Kulbokas EJ, Zody MC, Mauceli E, Xie X, Breen M, Wayne RK, Ostrander EA, Ponting CP, Galibert F, Smith DR, de Jong PJ, Kirkness E, Alvarez P, Biagi T, Brockman W, Butler J, Chin C-W, Cook A, Cuff J, Daly MJ, DeCaprio D, Gnerre S, et al: Genome sequence, comparative analysis and haplotype structure of the domestic dog. Nature 2005, 438:803-819.

15. Alkan C, Coe BP, Eichler EE: Genome structural variation discovery and genotyping. Nat Rev Genet 2011, 12:363-376.

16. Salmon Hillbertz NHC, Isaksson M, Karlsson EK, Hellmén E, Pielberg GR, Savolainen P, Wade CM, von Euler H, Gustafson U, Hedhammar A, Nilsson M, Lindblad-Toh K, Andersson L, Andersson G: Duplication of FGF3, FGF4, FGF19 and ORAOV1 causes hair ridge and predisposition to dermoid sinus in Ridgeback dogs. Nat Genet 2007, 39:1318-1320.

17. Parker HG, VonHoldt BM, Quignon P, Margulies EH, Shao S, Mosher DS, Spady TC, Elkahloun A, Cargill M, Jones PG, Maslen CL, Acland GM, Sutter NB, Kuroki K, Bustamante CD, Wayne RK, Ostrander EA: An expressed fgf4 retrogene is associated with breed-defining chondrodysplasia in domestic dogs. Science 2009, 325:995-998.

18. Chen WK, Swartz JD, Rush L, Alvarez CE: Mapping DNA structural variation in dogs. Genome Res 2009, 19:500-509.

19. Nicholas TJ, Cheng Z, Ventura M, Mealey K, Eichler EE, Akey JM: The genomic architecture of segmental duplications and associated copy number variants in dogs. Genome Res 2009, 19:491-499.

20. Nicholas TJ, Baker C, Eichler EE, Akey JM: A high-resolution integrated map of copy number polymorphisms within and between breeds of the modern domesticated dog. BMC Genomics 2011, 12:414.

21. Berglund J, Nevalainen EM, Molin A-M, Perloski M, André C, Zody MC, Sharpe T, Hitte C, Lindblad-Toh K, Lohi H, Webster MT: Novel origins of copy number variation in the dog genome. Genome Biol 2012, 13:R73.

22. Hastings PJ, Lupski JR, Rosenberg SM, Ira G: Mechanisms of change in gene copy number. Nat Rev Genet 2009, 10:551-564.

23. Mills RE, Walter K, Stewart C, Handsaker RE, Chen K, Alkan C, Abyzov A, Yoon SC, Ye K, Cheetham RK, Chinwalla A, Conrad DF, Fu Y, Grubert F, Hajirasouliha I, Hormozdiari F, lakoucheva LM, lqbal Z, Kang S, Kidd JM, Konkel MK, Korn J, Khurana E, Kural D, Lam HYK, Leng J, Li R, Li Y, Lin C-Y, Luo $R$, et al: Mapping copy number variation by population-scale genome sequencing. Nature 2011, 470:59-65.

24. Muñoz-Fuentes V, Di Rienzo A, Vilà C: Prdm9, a major determinant of meiotic recombination hotspots, is not functional in dogs and their wild relatives, wolves and coyotes. PLoS One 2011, 6:e25498.

25. Axelsson E, Webster MT, Ratnakumar A, Ponting CP, Lindblad-Toh K: Death of PRDM9 coincides with stabilization of the recombination landscape in the dog genome. Genome Res 2012, 22:51-63.

26. Rueda OM, Díaz-Uriarte R: Flexible and accurate detection of genomic copy-number changes from aCGH. PLoS Comput Biol 2007, 3:e122.

27. Stranger BE, Forrest MS, Dunning M, Ingle CE, Beazley C, Thorne N, Redon R, Bird CP, de Grassi A, Lee C, Tyler-Smith C, Carter N, Scherer SW, Tavaré S, Deloukas P, Hurles ME, Dermitzakis ET: Relative impact of nucleotide and copy number variation on gene expression phenotypes. Science 2007, 315:848-853.

28. Dempster A, Laird N, Rubin D: Maximum likelihood from incomplete data via the EM algorithm. J R Stat Soc 2007, 39:1-38.

29. Freedman AH, Gronau I, Schweizer RM, Ortega-Del Vecchyo D, Han E, Silva PM, Galaverni M, Fan Z, Marx P, Lorente-Galdos B, Beale H, Ramirez O, Hormozdiari F, Alkan C, Vilà C, Squire K, Geffen E, Kusak J, Boyko AR, Parker HG, Lee C, Tadigotla V, Siepel A, Bustamante CD, Harkins TT, Nelson SF, Ostrander EA, Marques-Bonet T, Wayne RK, Novembre J: Genome sequencing highlights the dynamic early history of dogs. PLOS Genet 2014, 10:e1004016.

30. Redon $R$, Ishikawa $S$, Fitch KR, Feuk L, Perry GH, Andrews TD, Fiegler $H$, Shapero MH, Carson AR, Chen W, Cho EK, Dallaire S, Freeman JL, González JR, Gratacòs M, Huang J, Kalaitzopoulos D, Komura D, MacDonald JR, Marshall CR, Mei R, Montgomery L, Nishimura K, Okamura K, Shen F, Somerville MJ, Tchinda J, Valsesia A, Woodwark C, Yang F, et al: Global variation in copy number in the human genome. Nature 2006 444:444-454.

31. Conrad DF, Pinto D, Redon R, Feuk L, Gokcumen O, Zhang Y, Aerts J, Andrews TD, Barnes C, Campbell P, Fitzgerald T, Hu M, Ihm CH, Kristiansson K, Macarthur DG, Macdonald JR, Onyiah I, Pang AWC, Robson S, Stirrups K, Valsesia A, Walter K, Wei J, Tyler-Smith C, Carter NP, Lee C, Scherer SW, Hurles ME: Origins and functional impact of copy number variation in the human genome. Nature 2010, 464:704-712.

32. Björnerfeldt $\mathrm{S}$, Webster MT, Vilà C: Relaxation of selective constraint on dog mitochondrial DNA following domestication. Genome Res 2006, 16:990-994.

33. Song Y, Altarejos J, Goodarzi MO, Inoue H, Guo X, Berdeaux R, Kim J-H Goode J, Igata M, Paz JC, Hogan MF, Singh PK, Goebel N, Vera L, Miller N, Cui J, Jones MR, Chen Y-DI, Taylor KD, Hsueh WA, Rotter Jl, Montminy M: CRTC3 links catecholamine signalling to energy balance. Nature 2010, 468:933-939.

34. Switonski M, Mankowska M: Dog obesity - the need for identifying predisposing genetic markers. Res Vet Sci 2013, 95:831-836.

35. Jin SL, Richard FJ, Kuo WP, D'Ercole AJ, Conti M: Impaired growth and fertility of CAMP-specific phosphodiesterase PDE4D-deficient mice. Proc Natl Acad Sci U S A 1999, 96:11998-12003.

36. Rimbault M, Beale HC, Schoenebeck JJ, Hoopes BC, Allen JJ, Kilroy-Glynn P, Wayne RK, Sutter NB, Ostrander EA: Derived variants at six genes explain nearly half of size reduction in dog breeds. Genome Res 2013, 23:1985-1995

37. Landry J-M: El Lobo. Barcelona: Omega; 2004

38. Rutten K, Misner DL, Works M, Blokland A, Novak TJ, Santarelli L, Wallace TL: Enhanced long-term potentiation and impaired learning in phosphodiesterase 4D-knockout (PDE4D) mice. Eur J Neurosci 2008, 28:625-632.

39. O'Connor V, Houtman SH, De Zeeuw Cl, Bliss TVP, French PJ: Eml5, a novel WD40 domain protein expressed in rat brain. Gene 2004, 336:127-137.

40. Chen J, Lee G, Fanous AH, Zhao Z, Jia P, O'Neill A, Walsh D, Kendler KS Chen $X$ : Two non-synonymous markers in PTPN21, identified by genome-wide association study data-mining and replication, are associated with schizophrenia. Schizophr Res 2011, 131:43-51.

41. Griswold AJ, Ma D, Cukier HN, Nations LD, Schmidt MA, Chung R-H, Jaworsk JM, Salyakina D, Konidari I, Whitehead PL, Wright HH, Abramson RK, Williams SM, Menon R, Martin ER, Haines JL, Gilbert JR, Cuccaro ML, Pericak-Vance MA: Evaluation of copy number variations reveals novel candidate genes in autism spectrum disorder-associated pathways. Hum Mol Genet 2012, 21:3513-3523.

42. Fletcher CF, Okano HJ, Gilbert DJ, Yang Y, Yang C, Copeland NG, Jenkins NA, Darnell RB: Mouse chromosomal locations of nine genes encoding homologs of human paraneoplastic neurologic disorder antigens. Genomics 1997, 45:313-319.

43. Yamada K, Iwayama Y, Hattori E, Iwamoto K, Toyota T, Ohnishi T, Ohba H, Maekawa M, Kato T, Yoshikawa T: Genome-wide association study of schizophrenia in Japanese population. PLoS One 2011, 6:e20468.

44. Fajardo-Serrano A, Wydeven $N$, Young $D$, Watanabe M, Shigemoto $R$, Martemyanov KA, Wickman K, Luján R: Association of Rgs7/G $\beta 5$ complexes with girk channels and GABAB receptors in hippocampal CA1 pyramidal neurons. Hippocampus 2013, 23:1231-1245. 
45. Kong W, Mou X, Liu Q, Chen Z, Vanderburg CR, Rogers JT, Huang X: Independent component analysis of Alzheimer's DNA microarray gene expression data. Mol Neurodegener 2009, 4:5.

46. Hare B, Brown M, Williamson C, Tomasello M: The domestication of social cognition in dogs. Science 2002, 298:1634-1636.

47. Topál J, Gergely G, Erdohegyi A, Csibra G, Miklósi A: Differential sensitivity to human communication in dogs, wolves, and human infants. Science 2009, 325:1269-1272.

48. Miklósi A, Topál J: What does it take to become "best friends"? Evolutionary changes in canine social competence. Trends Cogn Sci 2013, 17:287-294

49. Li Y, Vonholdt BM, Reynolds A, Boyko AR, Wayne RK, Wu D-D, Zhang Y-P. Artificial selection on brain-expressed genes during the domestication of dog. Mol Biol Evol 2013, 30:1867-1876.

50. Mi H, Muruganujan A, Thomas PD: PANTHER in 2013: modeling the evolution of gene function, and other gene attributes, in the context of phylogenetic trees. Nucleic Acids Res 2013, 41(Database issue):D377-D386.

doi:10.1186/1471-2164-15-465

Cite this article as: Ramirez et al:: Analysis of structural diversity in wolflike canids reveals post-domestication variants. BMC Genomics

2014 15:465

\section{Submit your next manuscript to BioMed Central and take full advantage of:}

- Convenient online submission

- Thorough peer review

- No space constraints or color figure charges

- Immediate publication on acceptance

- Inclusion in PubMed, CAS, Scopus and Google Scholar

- Research which is freely available for redistribution 